\title{
Endophthalmitis caused by Mycobacterium houstonense: case report
}

\author{
Xin Che ${ }^{\dagger}$, Qingjian Li ${ }^{\dagger}$, Luoziyi Wang, Jing Jiang, Xuzhong Shen, Yiwen Qian ${ }^{*}$ and Zhiliang Wang ${ }^{*}$
}

\begin{abstract}
Background: Mycobacterium houstonense is rapidly growing mycobacteria (RGM) that belongs to M. fortuitum group. So far, there have been few associated reports of human diseases induced by M. houstonense worldwide.

Case presentation: We present a delayed-onset postoperative endophthalmitis caused by M. houstonense after glaucoma drainage implant (GDI) surgery. The ocular infection lasted for 2 months without appropriate treatment that developed into endophthalmitis and the patient underwent an emergency enucleation.

Conclusion: Implant erosion and a delay in diagnosis of ocular infection could lead to irreversible damage as observed in our case. Ophthalmologists should be alert for ocular RGM infection, and prompt laboratory diagnosis with initiation of effective multidrug therapy might prevent loss of vision.
\end{abstract}

Keywords: Mycobacteria houstonense, Rapidly growing mycobacteria (RGM), Glaucoma drainage implant, Conjunctival erosion, Endophthalmitis

\section{Background}

Currently, the species of rapidly growing mycobacteria (RGM) capable of producing disease in humans are grouped into six major taxonomic groups according to pigmentation and genetic relatedness. The major taxa are the Mycobacterium fortuitum group, M. chelonae/M. abscessus complex, M. smegmatis group, $M$. mucogenicum group, M. mageritense/M. wolinskyi, and the pigmented RGM. $M$. fortuitum group has historically included $M$. fortuitum, $M$. peregrinum, $M$. senegalense, M. porcinum, M. neworleansense, $M$. boenickei, M. houstonense, M. brisbanense, M. septicum, and M. setense [1].

Ocular infections caused by RGM are keratitis, scleritis, uveitis and endophthalmitis. The predisposing factors of ocular RGM infections include trauma, cataract surgery, intravitreal injection, corticosteroid use, endogenous endophthalmitis, glaucoma drainage implant (GDI) and systemic immunosuppression [2]. Endophthalmitis induced

\footnotetext{
*Correspondence: qianyiwenqueeny@163.com; ophwz|@163.com

${ }^{+}$Xin Che and Qingjian Li contributed equally to this work.

Department of Ophthalmology, Huashan Hospital of Fudan University, No.

12, Middle Urumqi Road, Shanghai 200040, China
}

by RGM is an uncommon condition encountered post ocular surgery or trauma, which is sight threatening, may be acquired through contamination of water or antiseptic solutions. Most RGM endophthalmitis cases reported in the literature are exogenous, most of which occurred following cataract surgery $[3,4]$, multiple corneal transplantation [5, 6], intravitreal triamcinolone injection [7], ocular trauma [8], GDI surgery [9], silico ne-filled eye [10].

Here, we present a case of delayed-onset postoperative endophthalmitis caused by $M$. houstonense after GDI surgery. The device of GDI is used to drain aqueous humor from the anterior chamber of the eye into the subconjunctival or suprachoroidal space in order to lower the intraocular pressure in glaucoma cases [11].

\section{Case presentation}

A 45-year-old man presented to our eye clinic with complains of unbearable pain in the left eye and headache. The patient had history of GDI surgery 3 years ago in his left eye with Ahmed glaucoma valve (AGV) implantation. He experienced pain of the left eye in early February, went to see doctors in mid-February with treatment of

(c) The Author(s). 2020 Open Access This article is licensed under a Creative Commons Attribution 4.0 International License, which permits use, sharing, adaptation, distribution and reproduction in any medium or format, as long as you give appropriate credit to the original author(s) and the source, provide a link to the Creative Commons licence, and indicate if changes were made. The images or other third party material in this article are included in the article's Creative Commons licence, unless indicated otherwise in a credit line to the material. If material is not included in the article's Creative Commons licence and your intended use is not permitted by statutory regulation or exceeds the permitted use, you will need to obtain permission directly from the copyright holder. To view a copy of this licence, visit http://creativecommons.org/licenses/by/4.0/ The Creative Commons Public Domain Dedication waiver (http://creativecommons.org/publicdomain/zero/1.0/) applies to the data made available in this article, unless otherwise stated in a credit line to the data. 


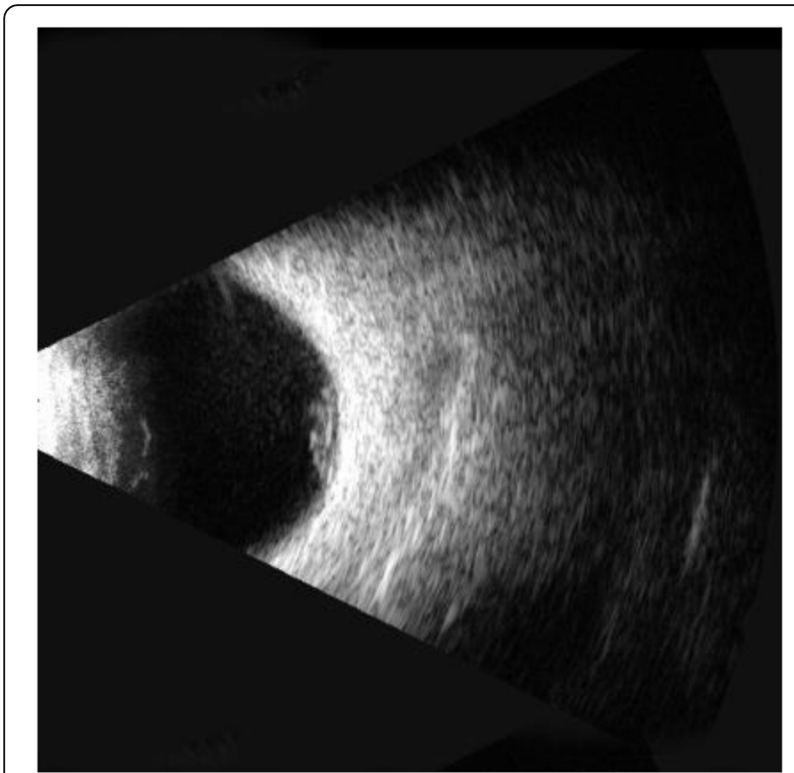

Fig. 1 B-ultrasound of the left eye showing mild vitreous opacity, and highly reflective masses protruding into the vitreous cavity

intravenous clindamycin $1.2 \mathrm{~g} / \mathrm{qd}$ for more than 10 days, the medication could temporarily relive the ocular pain. Due to COVID-19 pandemic, the patient did not consult doctors again, he took counter paracetamol by himself to relive pain. One month later he noticed displacement of AGV from his left eye, and then came to our eye clinic. The patient did not have any underlying diseases or medication history, his work was on freshwater aquaculture.

On ophthalmic examination, the best-corrected visual acuity (BCVA) was 20/20 (OD) and no light perception (OS), with intraocular pressure (IOP, normal range 10$21 \mathrm{mmHg}$ ) of $17 \mathrm{mmHg}(\mathrm{OD})$ and Tn (normal tension) + 1 (OS). The left eye showed conjunctival edema with congestion, corneal edema, hypopyon, and ocular fundus was not visible microscopically. No obvious abnormality was found in the right eye. The blood count revealed mild leukocytosis. Ocular ultrasonography showed vitreous opacity and mild atrophy of the left eye (Fig. 1). Thus the condition was presumptively diagnosed as infectious endophthalmitis. Considering the infection has resulted in severe intraocular tissue destruction and deteriorated vision, emergency enucleation of the infected eyeball was performed to prevent dissemination of the infection and sympathetic ophthalmia [12, 13]. During the surgery purulent exudates were observed, the ocular specimens and purulent exudates were subjected to microbiological investigation.

Within $48 \mathrm{~h}$, bacterial growth was observed in blood agar when cultured in $5 \% \mathrm{CO} 2$, at $35^{\circ} \mathrm{C}$ (Fig. 2b). ZiehlNeelsen staining of the monoclonal colonies revealed the presence of acid-fast bacilli (Fig. 2a), which was further identified as Mycobacterium houstonense by 16S rRNA and 16S-23S rRNA PCR, the primers are listed in Table 1. The amplified sequences of 16S rRNA and 16S-23S rRNA spacer region gene were compared with those available in the National Center for Biotechnology Information GenBank database, which revealed homology of 99.86 and 98.7\% with $M$. houstonense (GenBank sequence ID: KJ913784.1) respectively.

Antimicrobial susceptibility against $M$. houstonense was determined using minimal inhibitory concentration (MIC) by micro broth dilution method, the procedure and interpretation of the results were conducted in accordance with the CLSI M100 guidelines [14, 15]. The results showed that the strain was susceptible to levofloxacin, ciprofloxacin and amikacin, which was resistant to doxycycline, sulfamethoxazole and tobramycin. Subsequently, the patient was treated with a combination of intravenous amikacin $0.6 \mathrm{~g} / \mathrm{qd}$ and oral levofloxacin 0.5 $\mathrm{g} / \mathrm{qd}$ according to the drug sensitivity results for a week,

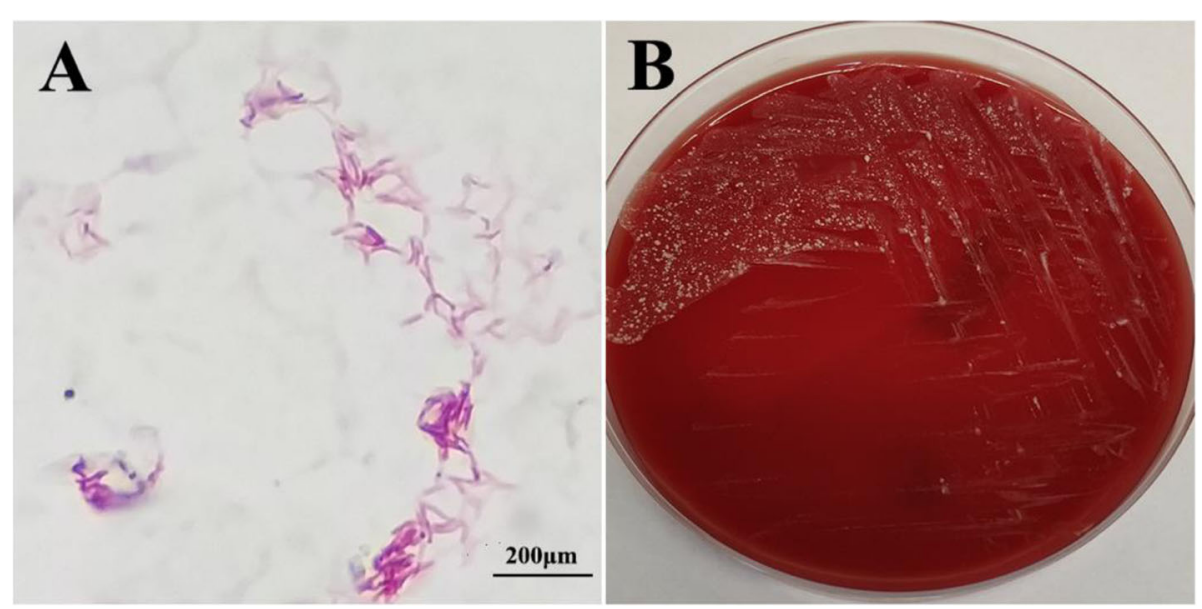

Fig. 2 a Ziehl-Neelsen staining showing acid-fast bacilli isolated from the ocular purulent exudates. b Monoclonal colonies on blood agar plates, which are round, smooth and beige color on the second day of incubation 
Table 1 Primers targeting16S rRNA and 16S-23S rRNA of $M$. houstonense for PCR

\begin{tabular}{lll}
\hline & Forward & Reverse \\
\hline 16S rRNA & AGAGTTTGATCMTGGCTCAG & GGTTACCTTGTTACGACTT \\
16S-23S & TTGTACACACCGCCCGTCA & TCTCGATGCCAAGGCATCCACC \\
rRNA & & \\
\hline
\end{tabular}

and then microbiological investigations on conjunctival sac secretion and the blood were tested negative. Subsequently the patient was discharged to see the infectious specialist, and the treatment regimen was changed to oral levofloxacin $0.5 \mathrm{~g}$ twice a day for 40 days, the patient was followed up for 4 months without any systemic and ocular abnormality.

\section{Discussion}

RGM is a rare cause of endophthalmitis. To date, our case was the first to demonstrate an ocular $M$. houstonense infection without any signs of systemic association. The patient had history of GDI surgery for refractory glaucoma, and experienced unbearable pain before AGV dislocation, thus we speculate that AGV tube exposure due to conjunctival dissolution could be the primary risk factor for the development of $M$. houstonense infection.

Literature states that $M$. houstonense are commonly found in water, and freshwater fish are potential reservoirs of RGM [16]. Intriguingly, the patient's occupation was aquaculture, thus it's concluded that the aquaculture water where he worked may be the source of RGM infection.

The diagnosis of RGM infection post-surgery is often delayed due to chronic and subtle course of disease without specific symptoms. Apart from patients with AIDS, disseminated RGM infection is usually associated with corticosteroid therapy, immunomodulating drugs and transplant patients [17]. In our case, the endophthalmitis lasted for almost 2 months without dissemination in the absence of appropriate treatment, which is probably because the patient has no any underlying diseases and endophthalmitis caused by RGM usually present as low-grade ocular inflammation [18].

Endophthalmitis is a rare complication following AGV implant surgery and results in poor vision, conjunctival erosions over the AGV tube has been reported in most cases and seem to represent a major risk factor for associated endophthalmitis [19]. The conventional treatments of endophthalmitis involve systemic and intravitreal injection of antibiotics, in combination with early pars plana vitrectomy surgery [20]. But currently, there has been no consensus on standard treatment for RGM infection. Lifelong follow-up of the eyes is very necessary to look for complications such as tube erosion after GDI surgeries, and prompt surgical intervention of conjunctival erosion is highly recommended. In patients with clinical signs and symptoms suggestive of endophthalmitis, microbiological investigations of vitreous with antibiotic susceptibility can offer rapid detection, which is of utmost importance to prevent devastating sequel of endophthalmitis.

\section{Abbreviations}

RGM: Rapidly growing mycobacteria; GDI: Glaucoma drainage implant; AGV: Ahmed glaucoma valve; BCVA: Best-corrected visual acuity;

MIC: Minimal inhibitory concentration

\section{Acknowledgements}

Not applicable.

\section{Authors' contributions}

Design of the study (ZLW, YWQ); data collection (XC, QJL, LZYW, JJ, XZS); preparation of the manuscript $(X C, Q J L)$. All authors have read and approved the manuscript to be published.

\section{Funding}

This study was supported by the National Natural Science Foundation of China NSFC, No. 81670868. The funders had no role in study design, data collection and analysis, decision on publish, or preparation of the manuscript.

\section{Availability of data and materials \\ Not applicable.}

\section{Ethics approval and consent to participate}

The treatment for the patient is performed under the tenets of the Declaration of Helsinki. The patient reported in the study provided written informed consent for the surgery.

\section{Consent for publication}

The patient enrolled in the study has signed the written informed consent for the publication of their clinical details along with the images.

\section{Competing interests}

The authors declare no competing financial interests.

Received: 11 August 2020 Accepted: 4 November 2020

Published online: 16 November 2020

\section{References}

1. Brown-Elliott BA, Philley JV. Rapidly Growing Mycobacteria. Microbiol Spectr. 2017;5(1). https://doi.org/10.1128/microbiolspec.TNMI7-0027-2016.

2. Shah $M$, Relhan $N$, Kuriyan $A E$, Davis $J$, Albini TA, Pathengay $A$, et al. Endophthalmitis caused by Nontuberculous Mycobacterium: clinical features, antimicrobial susceptibilities, and treatment outcomes. Am J Ophthalmol. 2016;168:150-6.

3. Marin-Casanova P, Calandria Amiguetti JL, Garcia-Martos P, Lozano Dominguez C, Sanabria BH, Puerto Alonso JL, et al. Endophthalmitis caused by Mycobacterium abscessus. Eur J Ophthalmol. 2003;13(9-10):800-2.

4. Hung JH, Huang $\mathrm{YH}$, Chang TC, Tseng SH, Shih MH, Wu JJ, et al. A cluster of endophthalmitis caused by Mycobacterium abscessus after cataract surgery. J Microbiol Immunol Infect. 2016;49(5):799-803.

5. Uy HS, Nguyen QD, Durand ML, Paton B, Foster CS. Infectious crystalline keratopathy and endophthalmitis secondary to Mycobacterium abscessus in a monocular patient with Stevens-Johnson syndrome. Am J Ophthalmol. 1999:127(2):209-10.

6. Chang V, Karp CL, Yoo SH, Ide T, Budenz DL, Kovach JL, et al. Mycobacterium abscessus endophthalmitis after Descemet's stripping with automated endothelial keratoplasty. Cornea. 2010;29(5):586-9.

7. Benz MS, Murray TG, Dubovy SR, Katz RS, Eifrig CW. Endophthalmitis caused by Mycobacterium chelonae abscessus after intravitreal injection of triamcinolone. Arch Ophthalmol. 2003;121(2):271-3.

8. Rolfe NE, Garcia C, Widen RH, Taylor SP. Rapid diagnosis of Mycobacterium abscessus endophthalmitis. J Med Microbiol. 2013;62(Pt 7):1089-91. 
9. Rao A, Wallang B, Padhy TR, Mittal R, Sharma S. Dual infection by streptococcus and atypical mycobacteria following Ahmed glaucoma valve surgery. Semin Ophthalmol. 2013;28(4):233-5.

10. Suganeswari G, Shah D, Anand AR. Intravitreal piperacillin-tazobactam in endophthalmitis caused by Mycobacterium abscessus in silico ne-filled eye: a case report. Indian J Ophthalmol. 2020;68(7):1471-3.

11. Valenzuela F, Oportus MJ, Perez Cl, Mellado F, Cartes C, Villarroel F, et al. Ahmed glaucoma drainage implant surgery in the management of refractory uveitic glaucoma: long-term follow up. Arch Soc Esp Oftalmol. 2018;93(9):431-8.

12. Pinitpuwadol W, Sarunket S, Boonsopon S, Tesavibul N, Choopong P. Lateonset postoperative Mycobacterium haemophilum endophthalmitis masquerading as inflammatory uveitis: a case report. BMC Infect Dis. 2018; 18(1):70

13. Lu X, Ng DS, Zheng K, Peng K, Jin C, Xia H, et al. Risk factors for endophthalmitis requiring evisceration or enucleation. Sci Rep. 2016;6:28100.

14. <M100ED29-2019_Decrypted(1).pdf>.

15. Institute; CLS. Clinical and Laboratory Standards Institute (2011) Susceptibility Testing of Mycobacteria, Nocardiae, and Other Aerobic Actinomycetes; Approved Standard - Second Edition M24-A2. 2011.

16. Lorencova A, Klanicova B, Makovcova J, Slana I, Vojkovska H, Babak V, et al. Nontuberculous mycobacteria in freshwater fish and fish products intended for human consumption. Foodborne Pathog Dis. 2013;10(6):573-6.

17. Lopez-Luis BA, Sifuentes-Osornio J, Perez-Gutierrez MT, Chavez-Mazari B, Bobadilla-Del-Valle M, Ponce-de-Leon A. Nontuberculous mycobacterial infection in a tertiary care center in Mexico, 2001-2017. Braz J Infect Dis. 2020;24(3):213-20.

18. Garg P. Fungal, mycobacterial, and Nocardia infections and the eye: an update. Eye (Lond). 2012;26(2):245-51.

19. Al-Torbak AA, Al-Shahwan S, Al-Jadaan I, Al-Hommadi A, Edward DP. Endophthalmitis associated with the Ahmed glaucoma valve implant. Br J Ophthalmol. 2005;89(4):454-8.

20. Xu K, Chin EK, Bennett SR, Williams DF, Ryan EH, Dev S, et al. Endophthalmitis after Intravitreal injection of vascular endothelial growth factor inhibitors: management and visual outcomes. Ophthalmology. 2018; 125(8):1279-86.

\section{Publisher's Note}

Springer Nature remains neutral with regard to jurisdictional claims in published maps and institutional affiliations.

Ready to submit your research? Choose BMC and benefit from:

- fast, convenient online submission

- thorough peer review by experienced researchers in your field

- rapid publication on acceptance

- support for research data, including large and complex data types

- gold Open Access which fosters wider collaboration and increased citations

- maximum visibility for your research: over $100 \mathrm{M}$ website views per year

At $\mathrm{BMC}$, research is always in progress.

Learn more biomedcentral.com/submissions 